\title{
Secretin-induced Duodenal Aspirate of Pancreatic Juice (SIDA): Utility of Commercial Genetic Analysis
}

\author{
RACHEL E. SIMPSON ${ }^{1}$, MICHELE YIP-SCHNEIDER ${ }^{1,2}$, KATELYN F. FLICK $^{1}$, \\ MAZHAR SOUFI ${ }^{1}$, EUGENE P. CEPPA ${ }^{1,2}$, MOHAMMAD A. AL-HADDAD $^{2,3}$, \\ JEFFREY J. EASLER ${ }^{3}$, STUART SHERMAN ${ }^{3}$, JOHN M. DEWITT ${ }^{3}$ and C. MAX SCHMIDT $1,2,4,5,6$ \\ ${ }^{1}$ Department of Surgery, Indiana University School of Medicine, Indianapolis, IN, U.S.A.; \\ ${ }^{2}$ Indiana University Health Pancreatic Cyst and Cancer Early Detection Center, Indianapolis, IN, U.S.A.; \\ ${ }^{3}$ Department of Medicine, Division of Gastroenterology, \\ Indiana University School of Medicine, Indianapolis, IN, U.S.A.; \\ ${ }^{4}$ Department of Biochemistry/Molecular Biology, Indiana University School of Medicine, Indianapolis, IN, U.S.A.; \\ ${ }^{5}$ Walther Oncology Center, Indianapolis, IN, U.S.A.; \\ ${ }^{6}$ Indiana University Simon Cancer Center, Indianapolis, IN, U.S.A.
}

\begin{abstract}
Background: Secretin-induced duodenal aspiration (SIDA) of pancreatic duct fluid has been proposed for pancreatic neoplasm screening in very highrisk patients. We sought to determine the clinical yield and safety of commercially-analyzed SIDA samples in patients at moderately elevated risk. Patients and Methods: A prospectively maintained institutional database of pancreatic fluid DNA profiles was retrospectively reviewed. Results: Fifty-seven patients underwent SIDA testing, most commonly for intraductal papillary mucinous neoplasms $(n=43)$ and not otherwise specified solitary cysts $(n=9)$. SIDA mutation yield was low compared to 37 concomitant endoscopic ultrasound-guided fine needle aspiration (EUSFNA) samples of pancreatic fluid: KRAS (2.5\% vs. 40.0\%), GNAS (2.6\% vs. $11.1 \%)$ and allelic loss of heterozygosity (3.1\% vs. 0\%). Patients undergoing SIDA alone experienced no complications while 3 patients with concomitant EUSFNA had post-procedural pancreatitis. Conclusion: The genetic yield of commercially-analyzed SIDA samples was relatively low in a moderately elevated risk cohort. SIDA testing may have a better safety profile than EUS-FNA.
\end{abstract}

This article is freely accessible online.

Correspondence to: C. Max Schmidt, Department of Surgery, Indiana University School of Medicine, 545 Barnhill Drive, Emerson Hall 129, Indianapolis, IN 46202, U.S.A. Tel: +1 3179488358, e-mail: maxschmi@iupui.edu

Key Words: Pancreatic juice, pancreatic neoplasms, pancreatic cyst, KRAS, GNAS, secretin-induced duodenal aspiration.
Pancreatic cancer is projected to be the $3^{\text {rd }}$ leading cause of cancer-related deaths in the United States (1). Histopathologic precursors to pancreatic cancer include microscopic pancreatic intraepithelial neoplasia (PanIN) and radiographically detectable cystic lesions such as intraductal papillary mucinous neoplasms (IPMN) (2). Predicting which of these preneoplastic lesions will progress to cancer is challenging, and preclinical detection is even more difficult. The current strategy for managing cystic lesions is outlined by the International Consensus Guidelines $(3,4)$ but lacks specificity for detecting high-grade (HGD) or invasive lesions $(5,6)$.

Because of the relatively low incidence of pancreatic cancer, most screening studies target very high-risk individuals with multi-generational familial pancreatic cancer or genetic syndromes associated with pancreatic cancer (7). EUS has been shown to be the most sensitive modality compared to cross-sectional imaging when detecting pancreatic lesions in asymptomatic, high-risk patients (8). EUS-fine needle aspiration (EUS-FNA) may be performed with subsequent fluid or tissue analysis. In general, cytology lacks sensitivity in detecting HGD or invasive disease $(9,10)$. Mutation in the KRAS oncogene detected by pancreatic fluid DNA analysis most consistently suggests mucinous differentiation (11), but, in combination with tumor suppressor gene mutations, has been associated with malignant pathology (12-16). Pancreatic fluid carcinoembryonic antigen (CEA) is mostly useful for determining mucinous origin rather than dysplastic grade (17-19). However, not all patients have lesions amenable to sampling, and the overall reported adverse event rate for EUS-FNA of pancreatic lesions is just under 3\% (20). While this figure is relatively low, this could represent a large number of affected patients at high-volume institutions. 
The collection of pancreatic juice from the duodenum after secretin stimulation (SIDA) has been suggested as a means for fluid analysis without the risk of pancreatic puncture. Importantly, this technique may allow pancreatic fluid analysis in patients with no detectable lesion (but heightened risk due to family history) or lesions too small to viably and safely sample by EUS-FNA. Prior studies have shown promise for duodenal fluid analysis in predicting the development of pancreatic cancer (21-23) or pre-malignant pancreatic cysts (24); however, these were largely from a single institution focused on the high-risk population.

In the present study, we evaluate the utility of commercially available genetic analysis of SIDA samples collected from patients at moderately elevated risk - thus lower than prior studies - based upon the presence of either pancreatic lesions or a family history ( $\geq 1$, first degree relative) of pancreatic cancer/genetic syndrome. Additionally, we compare the safety of SIDA technique to that of EUS-FNA.

\section{Patients and Methods}

Patient population and sample collection. A prospectively maintained single-institutional database of patient pancreatic fluid DNA profiles was retrospectively reviewed from March 2016 (start date of this protocol) through February 2018. All patients underwent endoscopic evaluation using a secretin-induced duodenal aspiration of pancreatic fluid (SIDA) protocol - aspiration of all gastric contents, administration of $16 \mathrm{mcg}$ of intravenous secretin, followed $10 \mathrm{~min}$ later by aspiration of duodenal/pancreatic fluid at or near the ampulla (25). All samples were sent to Interpace Diagnostics Inc. (Parsippany, NJ, USA) for commercially available genetic analysis. Patients with concomitant EUS-FNA of pancreatic cyst/main duct fluid were noted. Data were gathered and recorded in accordance with the Indiana University Institutional Review Board.

Genetic analysis. Interpace Diagnostics utilizes the classic Sanger Sequencing method to detect oncogene point mutations; allelic LOH is determined using capillary electrophoresis to detect microsatellite imbalance (personal correspondence, Dr. Sydney D. Finkelstein, Chief Scientific Officer \& Medical Director, Interpace Diagnostics). Genetic analysis of SIDA samples by Interpace Diagnostics included the following assessments as provided on the patient report:

DNA quantity: values indicated as "low," "mildly elevated," "moderately elevated," or "greatly elevated". All but "low quantity" were considered elevated in this study.

DNA quality: indicated as "poor" or "good" quality.

Oncogene mutations: KRAS (codons 12,13) and GNAS (codon 201) mutations were assessed for presence and clonality. "High clonality" is indicated when $>75 \%$ of DNA in a sample is affected by the mutation (26).

Tumor suppressor gene mutations: described as allelic loss of heterozygosity (LOH). A panel of 16 genes (VHL, OGG1, PTEN, MXI1, TP53, SMAD4, DCC, CDKN2A, RNF43, NME1, PSEN2, TFF1, CMM1v, MCC, APC, NF2) were assessed for presence and clonality (27).

No amplification: sample wass insufficient to perform genetic mutational analysis.
Overall behavior: genetic features combined with clinical factors generated an overall behavior designation/risk score - Benign, Statistically Indolent, Statistically Higher Risk, Aggressive (28). Determination of clinical variables and outcomes. The electronic medical record was retrospectively reviewed for additional clinical data. Family history included any first degree relative with a known diagnosis of pancreatic cancer, and one patient with known BRCA2 mutation. Radiographic findings were based on the most recent cross-sectional imaging prior to SIDA sample collection. Presumed diagnosis at the time of SIDA sampling was determined using imaging, clinical history, prior surgical pathology, prior biopsies or cyst fluid analysis. The presumed diagnosis of IPMN required the presence of multifocal cystic lesions; cysts with documented connection to the main pancreatic duct; and/or cyst fluid mucin, KRAS/GNAS mutation, carcinoembryonic antigen (CEA) $>192 \mathrm{ng} / \mathrm{ml}$, or cytology suggestive of IPMN. Solitary cysts lacking these features were designated as "not otherwise specified" (NOS). Overall outcomes were determined to be benign or malignant based on clinical follow up, available cross-sectional imaging or endoscopic evaluation with evidence of invasive mass lesion, surgical pathology positive for cancer, cytology or biopsy results concerning for malignancy.

Statistical analysis. Descriptive statistics were calculated for the patient cohort. Continuous variables were assessed using the Mann$U$ Whitney test, whereas Fisher's Exact test was used to compare categorical variables including mutation incidence (IBM SPSS software version 2.4, Armonk, NY, USA).

\section{Results}

Full cohort SIDA samples. A total of 57 patients, considered at moderately elevated risk of developing pancreatic cancer compared to the general population, underwent SIDA with genetic testing of pancreatic fluid. Average age at time of procedure was 67.0 years old, and 43 patients $(75.4 \%)$ were female. Twelve patients $(21.1 \%)$ were noted to have a family history of pancreatic cancer/genetic syndrome $(\geq 1$, first degree relative): 3 had no pancreatic morphologic changes, 7 had likely IPMN, and 2 had "not otherwise specified" (NOS) solitary cysts. Of the remaining 45 patients $(78.9 \%)$ with no family history of pancreatic cancer/genetic syndrome, 36 had presumed diagnoses of IPMN, 7 had NOS solitary cysts, and 2 had presumed diagnosis of pancreatitis. Mean main pancreatic duct diameter at the time of endoscopy was $2.6 \pm 1.4 \mathrm{~mm}(\mathrm{n}=32)$. Mean index cyst size was $13.3 \pm 9.1 \mathrm{~mm}(\mathrm{n}=50)$.

SIDA samples from the 57 patients were assigned overall behavior scores of low malignant potential. Specifically, for the 12 patients with family history (higher end of the risk spectrum for this study), $9(75 \%)$ were benign and $3(25 \%)$ were statistically indolent. For the 45 lower risk patients without family history, $36(80 \%)$ were benign and 9 (20\%) statistically indolent. Most patients displayed an elevated quantity of DNA [10 of $12(83.3 \%)$ with family history; 29 of $43(67.4 \%)$ without family history], while $50 \%$ (6 of 12) 
Table I. Genetic features of EUS-FNA and SIDA samples by indication for endoscopy.

\begin{tabular}{|c|c|c|c|c|c|c|c|c|c|c|c|}
\hline \multirow[b]{2}{*}{ Indication } & \multirow[b]{2}{*}{$\mathrm{N}$} & \multicolumn{2}{|c|}{$\begin{array}{c}\text { Elevated quantity } \\
\text { DNA }\end{array}$} & \multicolumn{2}{|c|}{$\begin{array}{c}\text { Elevated quality } \\
\text { DNA }\end{array}$} & \multicolumn{2}{|c|}{ KRAS } & \multicolumn{2}{|c|}{ GNAS } & \multicolumn{2}{|c|}{$\mathrm{LOH}$} \\
\hline & & SIDA & EUS-FNA & SIDA & EUS-FNA & SIDA & EUS-FNA & SIDA & EUS-FNA & SIDA & EUS-FNA \\
\hline \multirow[t]{2}{*}{ Family history } & 12 & $(10 / 12)$ & $(1 / 4)$ & $(6 / 12)$ & $(1 / 4)$ & $(0 / 12)$ & $(0 / 3)$ & $(0 / 9)$ & $(0 / 4)$ & $(0 / 11)$ & $(0 / 3)$ \\
\hline & & $83.3 \%$ & $25.0 \%$ & $50.0 \%$ & $25.0 \%$ & $0 \%$ & $0 \%$ & $0 \%$ & $0 \%$ & $0 \%$ & $0 \%$ \\
\hline \multirow[t]{2}{*}{ No morphologic changes } & 3 & $(3 / 3)$ & $(0 / 1)$ & $(2 / 3)$ & $(0 / 1)$ & $(0 / 3)$ & $(0 / 1)$ & $(0 / 3)$ & $(0 / 1)$ & $(0 / 3)$ & $(0 / 1)$ \\
\hline & & $100 \%$ & $0 \%$ & $66.7 \%$ & $0 \%$ & $0 \%$ & $0 \%$ & $0 \%$ & $0 \%$ & $0 \%$ & $0 \%$ \\
\hline \multirow[t]{2}{*}{ IPMN } & 7 & $(5 / 7)$ & $(1 / 3)$ & $(2 / 7)$ & $(1 / 3)$ & $(0 / 7)$ & $(0 / 2)$ & $(0 / 5)$ & $(0 / 3)$ & $(0 / 6)$ & $(0 / 2)$ \\
\hline & & $71.4 \%$ & $33.3 \%$ & $28.6 \%$ & $33.3 \%$ & $0 \%$ & $0 \%$ & $0 \%$ & $0 \%$ & $0 \%$ & $0 \%$ \\
\hline \multirow{2}{*}{$\begin{array}{l}\text { Not otherwise specified } \\
\text { solitary cyst }\end{array}$} & 2 & $(2 / 2)$ & $(0 / 0)$ & $(2 / 2)$ & $(0 / 0)$ & $(0 / 2)$ & $(0 / 0)$ & $(0 / 1)$ & $(0 / 0)$ & $(0 / 2)$ & $(0 / 0)$ \\
\hline & & $100 \%$ & $0 \%$ & $100 \%$ & $0 \%$ & $0 \%$ & $0 \%$ & $0 \%$ & $0 \%$ & $0 \%$ & $0 \%$ \\
\hline \multirow[t]{2}{*}{ No family history } & 45 & $(29 / 43)$ & $(11 / 33)$ & $(20 / 43)$ & $(9 / 33)$ & $(1 / 40)$ & $(12 / 30)$ & $(1 / 38)$ & $(3 / 27)$ & $(1 / 32)$ & $(0 / 24)$ \\
\hline & & $67.4 \%$ & $33.3 \%$ & $46.5 \%$ & $27.3 \%$ & $2.5 \%$ & $40.0 \%$ & $2.6 \%$ & $11.1 \%$ & $3.1 \%$ & $0 \%$ \\
\hline \multirow[t]{2}{*}{ IPMN } & 36 & $(24 / 35)$ & $(8 / 29)$ & $(17 / 35)$ & $(7 / 29)$ & $(1 / 33)$ & $(11 / 26)$ & $(1 / 31)$ & $(2 / 23)$ & $(1 / 26)$ & $(0 / 20)$ \\
\hline & & $67.4 \%$ & $27.6 \%$ & $48.6 \%$ & $24.1 \%$ & $3.0 \%$ & $42.3 \%$ & $3.2 \%$ & $8.7 \%$ & $3.8 \%$ & $0 \%$ \\
\hline \multirow{4}{*}{$\begin{array}{l}\text { Not otherwise specified } \\
\text { solitary cyst } \\
\text { Pancreatitis }\end{array}$} & 7 & $(3 / 6)$ & $(3 / 4)$ & $(3 / 6)$ & $(2 / 4)$ & $(0 / 6)$ & $(1 / 4)$ & $(0 / 6)$ & $(1 / 4)$ & $(0 / 6)$ & $(0 / 4)$ \\
\hline & & $50 \%$ & $75.0 \%$ & $50.0 \%$ & $50.0 \%$ & $0 \%$ & $25.0 \%$ & $0 \%$ & $25.0 \%$ & $0 \%$ & $0 \%$ \\
\hline & 2 & $(2 / 2)$ & $(0 / 0)$ & $(0 / 2)$ & $(0 / 0)$ & $(0 / 1)$ & $(0 / 0)$ & $(0 / 1)$ & $(0 / 0)$ & $(0 / 0)$ & $(0 / 0)$ \\
\hline & & $100 \%$ & $0 \%$ & $0 \%$ & $0 \%$ & $0 \%$ & $0 \%$ & $0 \%$ & $0 \%$ & $0 \%$ & $0 \%$ \\
\hline
\end{tabular}

Elevated quantity DNA: All but low quantity DNA; Good quality DNA: all but poor quality DNA. Results only include patient samples that were amplified or tested.

and $46.5 \%$ (20 of 43 ) of the respective groups showed good quality of DNA (Table I). Overall mutation yield from SIDA samples was low. Only 1 of $40(2.5 \%)$ samples in the no family history group displayed a low clonality KRAS mutation; the same sample (1of 38, 2.6\%) possessed a low clonality GNAS mutation. This patient had a presumed preprocedure diagnosis of IPMN based on radiographic cyst morphology and the presence of extracellular mucin in pancreatic fluid. Low clonality allelic LOH was detected only in 1 of $32(3.1 \%)$ in the no family history group.

All 57 patients were found to have a benign outcome at the most recent follow-up. For 54 patients, the mean followup with available radiographic imaging was 29.4 \pm 8.6 months. Of the remaining 3 patients, the last evaluation with imaging was at the time of SIDA sampling, so this outcome was determined by cytology, overall clinical suspicion, and genetic testing results.

Concomitant EUS-FNA samples. Of the 57 patients that underwent SIDA sample analysis, 37 concomitant EUS-FNA samples ( $\mathrm{n}=4$, family history; 33, no family history) had DNA profiling (Table I). The overall behavior scores were almost entirely low-risk - family history: $4(100 \%)$ benign; no family history: $20(60.6 \%)$ benign, $12(36.4 \%)$ statistically indolent, $1(3.0 \%)$ statistically higher risk. In EUS-FNA samples, the frequency of high quantity (25\% family history, $p=0.063 ; 33.3 \%$ no family history, $p=0.005$ ) and good quality DNA ( $25 \%$ family history, $p=0.584 ; 27.3 \%$ no family history, $p=0.101$ ) was lower than that of SIDA. In the no family history group, EUS-FNA samples demonstrated a higher detection rate for mutated KRAS $(40.0 \% ; p<0.0001)$ and GNAS $(11.1 \% ; p=0.299)$ compared to SIDA. In contrast to the SIDA results, no allelic $\mathrm{LOH}$ was detected in this group on EUS-FNA fluid analysis $(0 \% ; p=1.000)$.

In general, SIDA and EUS-FNA DNA profiles did not correlate. None of the KRAS or GNAS mutations detected by EUS-FNA were noted on SIDA sample analysis. Likewise, the patient with both low clonality KRAS and GNAS mutations detected on SIDA fluid analysis did not display these features on EUS-FNA sampling. The single patient with an elevated overall malignancy risk score on EUS-FNA (statistically higher risk) was deemed statistically indolent by SIDA. This was the only patient to undergo surgical resection following SIDA sampling, and was found to have a low-grade mixed-type IPMN.

CEA levels were examined in 14 patients with SIDA and concomitant EUS-FNA samples simultaneously tested. Eleven patients $(78.6 \%)$ showed a lower CEA level in the SIDA sample than that of EUS-FNA. CEA levels were similar in 2 patients and higher in the SIDA sample for 1 patient. Median CEA levels for the paired results were significantly lower in SIDA samples than EUS-FNA [61.0 (6.0-138.0) vs. 436.0 (2.2-102010.0) ng/ml; $p=0.029$ ] (Figure 1).

Post-procedural adverse events. Only 3 patients had postprocedural adverse events. Two patients were diagnosed with pancreatitis with characteristic abdominal pain and elevated serum pancreatic enzymes, requiring inpatient treatment for $<1$ 


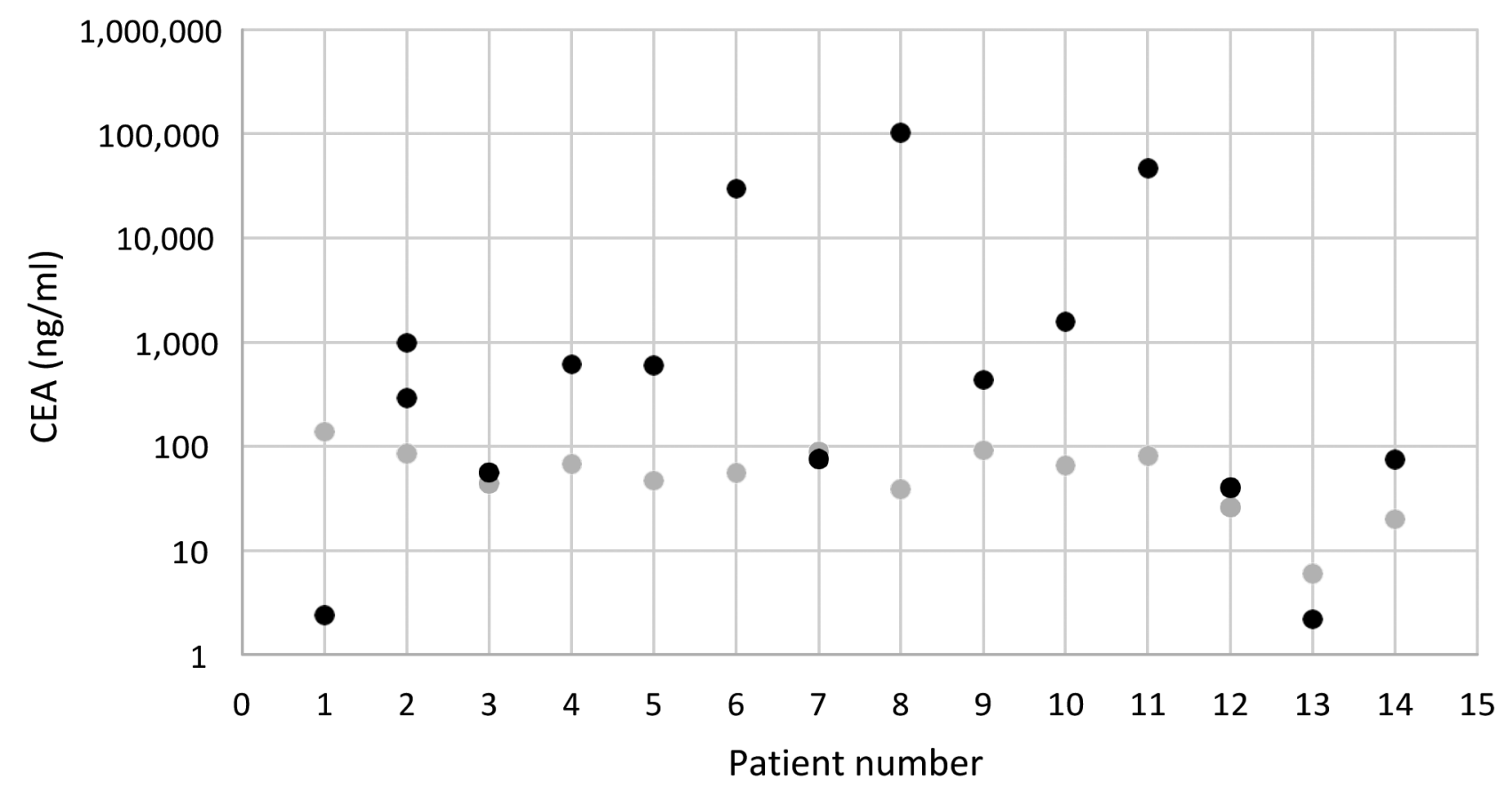

Figure 1. CEA concentrations ( $\mathrm{ng} / \mathrm{ml}$ ) for concomitant SIDA (gray dot) and EUS-FNA (black dot) samples by individual patient. Median CEA levels were significantly lower in SIDA samples than EUS-FNA [61.0 (6.0-138.0) vs. 436.0 (2.2-102010.0) $\mathrm{ng} / \mathrm{ml} ; \mathrm{p}=0.029]$.

week. The third patient had a presumed diagnosis of pancreatitis with characteristic abdominal pain and anorexia; however, serum pancreatic enzymes were not examined until 2 weeks post-endoscopy and were found to be normal at that time. Of note, each of these patients had concomitant EUS-FNA of pancreatic cyst or duct fluid at the time of SIDA. None of the 20 patients with SIDA alone experienced an adverse event.

\section{Discussion}

In the current study, we present a single-institution series of commercially-available SIDA fluid analyses. Much of the existing work examining duodenal collection of pancreatic fluid is from a single group using highly specialized sequencing technologies. Furthermore, these reports focus on a very highrisk population (patients with multi-generational family history of pancreatic cancer or genetic syndromes), leaving a gap in knowledge regarding patients with moderately elevated risk. Overall, the rate of mutation detection in the present study was much lower than that of the published literature.

Specifically, mutated KRAS was detected in only $1(2.5 \%)$ of 40 SIDA samples with no family history of pancreatic cancer or germline mutation, in an individual with a presumed diagnosis of IPMN. This is significantly lower than the KRAS mutation rate, between $49.5 \%-63.9 \%$, reported for high-risk individuals (defined by multi-generational family history or germline mutation with predisposition to pancreatic cancer) undergoing screening $(21,29)$. For low-risk individuals with no significant familial predisposition, the rate of KRAS mutation depended on pancreatic morphology and ranged from $18.2 \%$ for normal pancreas to $44.4 \%$ for patients with chronic pancreatitis (21). Our results were most concordant with Iguchi et al., showing a low rate of KRAS mutation (2.4\%) in patients with benign pancreatic disease (30).

GNAS mutations were detected in the present study at a similarly low rate ( 1 of 38 patients tested, $2.6 \%$ ). In patients with a presumed diagnosis of IPMN, the reported rate of GNAS mutation ranged from 53\%-64.1\% (23, 24). For individuals undergoing screening for high-risk family history, but without a presumed diagnosis of IPMN, the incidence of GNAS mutation was lower (11.1\%-19.2\%) (21, $24)$. In a study by Kanda et al., $45.5 \%$ of small cysts $<5 \mathrm{~mm}$ (not meeting their designated size criteria for IPMN) and $0 \%$ of controls (without family history or IPMN diagnosis) revealed GNAS mutations (24).

Two main differences in study design may contribute to our observed lower mutation detection rate. First, our definition of family history ( $\geq 1$, first degree relative) differs from prior studies with much more stringent inclusion criteria defining "high-risk" (i.e. multi-generational family history of pancreatic cancer). Second, different sequencing techniques were employed. In the present study, commercially available genetic analysis by 
Interpace Diagnostics uses the classic, gold-standard method of Sanger Sequencing to detect oncogene point mutations. Prior studies utilized specialized methods such as pyrosequencing (21, $22,24,29)$, single-strand conformation polymorphism analysis (30), or digital next generation sequencing (23).

There are few studies examining the presence of tumor suppressor gene mutations in SIDA fluid. Yu et al. report the rate of tumor protein p53 (TP53) or SMAD4 mutations in patients with IPMN reached $30.4 \%$ (23). Another study found a positive association between TP53 mutation incidence and grade of dysplasia; no patients with low-grade IPMN or pancreatic intraepithelial neoplasia 1 (PanIN1) revealed TP53 mutations (22). We detected allelic LOH of tumor suppressor genes $(\mathrm{Chr} 17 \mathrm{q})$ in only one patient with presumed diagnosis of IPMN, consistent with our lower-risk patient cohort.

In the present study, the rate of high quantity DNA was significantly greater for samples gathered via SIDA compared to EUS-FNA. This is expected, as DNA from the pancreas, duodenum and biliary tree is collected during SIDA, compared to pure pancreatic fluid during EUS-FNA. Sadakari et al. have also reported higher concentrations of DNA from fluid collected in the duodenum versus directly from the pancreas. They propose that a higher level of nonpancreatic DNA may obscure the detection of low frequency pancreatic mutations (29). This may contribute to the low rate of mutations detected in our analysis.

Beyond genetic indicators, carcinoembryonic antigen (CEA) is the current leading biomarker in distinguishing between mucinous and non-mucinous cysts (17-19). We examined CEA levels in 14 patients with both SIDA and EUS-FNA pancreatic fluid tested for this biomarker. The majority of cases revealed the expected trend of diluted concentrations of CEA in SIDA fluid compared to EUS-FNA fluid. Taken together, based upon the higher yield of molecular and protein information, our findings support the continued use of EUS-FNA over commercially analyzed SIDA fluid for patients at moderately elevated risk due to potentially preneoplastic cystic lesions or family history.

Overall, we observed no correlation between genetic profiles detected on SIDA fluid versus concomitant EUS-FNA fluid analysis. Sadakari et al. performed a similar comparison but detected $79.3 \%$ of KRAS and $33.3 \%$ of GNAS mutations in both duodenal fluid and direct pancreatic duct fluid collections (29). We propose several explanations for the weaker correlation observed in our study. First, the majority of cyst/duct fluids ( $n=31$ of 37 total, 83.8\%), were fine-needle aspirated just before SIDA sampling, potentially depleting mutated DNA available for collection by SIDA. This simultaneous collection contrasts with that of Sadakari et al., in which the two collections were often separated by several days (29), theoretically allowing reconstitution of mutation-rich fluid within the pancreas. In addition, multiple cysts with unique mutations may be missed by cyst-specific EUS-FNA analysis but detected by SIDA fluid analysis. Similarly, a mutation in the main ductal system rather than a side branch/cyst, may be detected on SIDA fluid analysis but not on EUS-FNA. Finally, inadequate or unequal "flushing" of the side branches or cysts during secretin administration may occur, resulting in inadequate fluid collection.

Unique to Interpace Diagnostics fluid analysis is the provision of an overall malignancy risk score, combining clinical data with mutational data to predict the chance of cancer development (28). While our rate of mutation detection was lower than those of existing studies, all study patients were in fact overall predicted to have a "benign" or "statistically indolent" course. At the most recent follow-up, these predictions held true, as no patients had developed an overtly malignant lesion. Thus, the overall risk score that combines clinical and genetic data may be more predictive and clinically valuable than mutational data alone.

Our study has several limitations. Though DNA profile data were collected and stored retrospectively, other clinical, radiographic, and outcome data were gathered retrospectively. We used all available clinical information up to the time of SIDA fluid analysis to develop a most likely diagnosis; however, without surgical pathology, a true diagnosis cannot be certain. Similarly, outcome designation was dependent on clinical follow-up with radiographic imaging; without surgical pathology, one cannot be certain of the absence of malignancy.

The diagnostic yield of commercially-analyzed SIDA samples in the present study was relatively low, reflecting a population at only moderately elevated risk for pancreatic cancer. Importantly, these results represent those obtainable to the clinician without access to a specialized laboratory with advanced sequencing technologies. The safety profile of SIDA testing may be better than that of EUS-FNA with no reported complications for SIDA-only patients. Taken together, the clinical utility of commercially-analyzed SIDA samples in this population warrants further study.

\section{Conflicts of Interest}

The Authors declare no conflicts of interest.

\section{Authors' Contributions}

Drs. Schmidt, DeWitt, Simpson and Flick: conception/design of the work; data acquisition, analysis, and interpretation; manuscript drafting/revision/final approval; agreement to accountability. Drs. Yip-Schneider, Soufi, Ceppa, Al-Haddad, Easler and Sherman: data acquisition and/or interpretation; manuscript revision/final approval; agreement to accountability.

\section{References}

12019 estimates. American cancer society: Cancer statistics center. Available at: https://cancerstatisticscenter.cancer.org/?_ga=2.106271 747.1452595691.1548795895-915087983.1548795895 - ! 
2 Mohammed S, Van Buren G, $2^{\text {nd }}$ and Fisher WE: Pancreatic cancer: Advances in treatment. World J Gastroenterol 20(28): 9354-9360, 2014. PMID: 25071330. DOI: 10.3748/wjg.v20.i28.9354

3 Tanaka M, Fernandez-del Castillo C, Adsay V, Chari S, Falconi M, Jang JY, Kimura W, Levy P, Pitman MB, Schmidt CM, Shimizu M, Wolfgang CL, Yamaguchi $\mathrm{K}$ and Yamao $\mathrm{K}$ : International consensus guidelines 2012 for the management of ipmn and mcn of the pancreas. Pancreatology 12(3): 183-197, 2012. PMID: 22687371. DOI: 10.1016/j.pan.2012.04.004

4 Tanaka M, Fernandez-Del Castillo C, Kamisawa T, Jang JY, Levy P, Ohtsuka T, Salvia R, Shimizu Y, Tada M and Wolfgang CL: Revisions of international consensus fukuoka guidelines for the management of ipmn of the pancreas. Pancreatology 17(5): 738753, 2017. PMID: 28735806. DOI: 10.1016/j.pan.2017.07.007

5 Jang JY, Park T, Lee S, Kang MJ, Lee SY, Lee KB, Chang YR and Kim SW: Validation of international consensus guidelines for the resection of branch duct-type intraductal papillary mucinous neoplasms. Br J Surg 101(6): 686-692, 2014. PMID: 24668442. DOI: $10.1002 /$ bjs.9491

6 Al-Haddad MA, Kowalski T, Siddiqui A, Mertz HR, Mallat D, Haddad N, Malhotra N, Sadowski B, Lybik MJ, Patel SN, Okoh E, Rosenkranz L, Karasik M, Golioto M, Linder J and Catalano MF: Integrated molecular pathology accurately determines the malignant potential of pancreatic cysts. Endoscopy 47(2): 136142, 2015. PMID: 25314329. DOI: $10.1055 / \mathrm{s}-0034-1390742$

7 Ngamruengphong S and Canto MI: Screening for pancreatic cancer. Surg Clin North Am 96(6): 1223-1233, 2016. PMID: 27865274. DOI: 10.1016/j.suc.2016.07.016

8 Canto MI, Hruban RH, Fishman EK, Kamel IR, Schulick R, Zhang Z, Topazian M, Takahashi N, Fletcher J, Petersen G, Klein AP, Axilbund J, Griffin C, Syngal S, Saltzman JR, Mortele KJ, Lee J, Tamm E, Vikram R, Bhosale P, Margolis D, Farrell J, Goggins M and American Cancer of the Pancreas Screening C: Frequent detection of pancreatic lesions in asymptomatic high-risk individuals. Gastroenterology 142(4): 796-804; quiz e714-795, 2012. PMID: 22245846. DOI: 10.1053/j.gastro.2012.01.005

9 Suzuki R, Thosani N, Annangi S, Guha S and Bhutani MS: Diagnostic yield of eus-fna-based cytology distinguishing malignant and benign ipmns: A systematic review and metaanalysis. Pancreatology 14(5): 380-384, 2014. PMID: 25278308. DOI: 10.1016/j.pan.2014.07.006

10 Jeong SH, Yoon HH, Kim EJ, Kim YJ, Kim YS and Cho JH: High-resolution endoscopic ultrasound imaging and the number of needle passages are significant factors predicting high yield of endoscopic ultrasound-guided fine needle aspiration for pancreatic solid masses without an on-site cytopathologist. Medicine (Baltimore) 96(2): e5782, 2017. PMID: 28079803. DOI: $10.1097 / \mathrm{MD} .0000000000005782$

11 Thiruvengadam N and Park WG: Systematic review of pancreatic cyst fluid biomarkers: The path forward. Clin Transl Gastroenterol 6: e88, 2015. PMID: 26065716. DOI: 10.1038/ctg.2015.17

12 Winner M, Sethi A, Poneros JM, Stavropoulos SN, Francisco P, Lightdale CJ, Allendorf JD, Stevens PD and Gonda TA: The role of molecular analysis in the diagnosis and surveillance of pancreatic cystic neoplasms. JOP 16(2): 143-149, 2015. PMID: 25791547. DOI: $10.6092 / 1590-8577 / 2941$

13 Khalid A, McGrath KM, Zahid M, Wilson M, Brody D, Swalsky P, Moser AJ, Lee KK, Slivka A, Whitcomb DC and Finkelstein $\mathrm{S}$ : The role of pancreatic cyst fluid molecular analysis in predicting cyst pathology. Clin Gastroenterol Hepatol 3(10): 967-973, 2005. PMID: 16234041.

14 Khalid A, Zahid M, Finkelstein SD, LeBlanc JK, Kaushik N, Ahmad N, Brugge WR, Edmundowicz SA, Hawes RH and McGrath KM: Pancreatic cyst fluid DNA analysis in evaluating pancreatic cysts: A report of the panda study. Gastrointest Endosc 69(6): 1095-1102, 2009. PMID: 19152896. DOI: 10.1016/j.gie.2008.07.033

15 Schoedel KE, Finkelstein SD and Ohori NP: K-ras and microsatellite marker analysis of fine-needle aspirates from intraductal papillary mucinous neoplasms of the pancreas. Diagn Cytopathol 34(9): 605-608, 2006. PMID: 16900481. DOI: $10.1002 / d c .20511$

16 Simpson RE, Cockerill NJ, Yip-Schneider MT, Ceppa EP, House MG, Zyromski NJ, Nakeeb A, Al-Haddad MA and Schmidt CM: DNA profile components predict malignant outcomes in select cases of intraductal papillary mucinous neoplasm with negative cytology. Surgery 164(4): 712-718, 2018. PMID: 30139561. DOI: $10.1016 /$ j.surg.2018.05.033

17 Brugge WR: Cyst fluid: Moving beyond the carcinoembryonic antigen. Gastrointest Endosc 82(6): 1070-1071, 2015. PMID: 26264436. DOI: 10.1016/j.gie.2015.08.005

18 Correa-Gallego C, Warshaw AL and Fernandez-del Castillo C: Fluid cea in ipmns: A useful test or the flip of a coin? Am J Gastroenterol 104(3): 796-797, 2009. PMID: 19223886. DOI: 10.1038/ajg.2008.158

19 Kucera S, Centeno BA, Springett G, Malafa MP, Chen YA, Weber $\mathrm{J}$ and Klapman J: Cyst fluid carcinoembryonic antigen level is not predictive of invasive cancer in patients with intraductal papillary mucinous neoplasm of the pancreas. JOP 13(4): 409-413, 2012. PMID: 22797397. DOI: 10.6092/1590-8577/664

20 Zhu H, Jiang F, Zhu J, Du Y, Jin Z and Li Z: Assessment of morbidity and mortality associated with endoscopic ultrasoundguided fine-needle aspiration for pancreatic cystic lesions: A systematic review and meta-analysis. Dig Endosc 29(6): 667675, 2017. PMID: 28218999. DOI: 10.1111/den.12851

21 Eshleman JR, Norris AL, Sadakari Y, Debeljak M, Borges M, Harrington C, Lin E, Brant A, Barkley T, Almario JA, Topazian M, Farrell J, Syngal S, Lee JH, Yu J, Hruban RH, Kanda M, Canto MI and Goggins M: Kras and guanine nucleotide-binding protein mutations in pancreatic juice collected from the duodenum of patients at high risk for neoplasia undergoing endoscopic ultrasound. Clin Gastroenterol Hepatol 13(5): 963-969 e964, 2015. PMID: 25481712. DOI: 10.1016/j.cgh.2014.11.028

22 Kanda M, Sadakari Y, Borges M, Topazian M, Farrell J, Syngal S, Lee J, Kamel I, Lennon AM, Knight S, Fujiwara S, Hruban RH, Canto MI and Goggins M: Mutant tp53 in duodenal samples of pancreatic juice from patients with pancreatic cancer or high-grade dysplasia. Clin Gastroenterol Hepatol 11(6): 719-730 e715, 2013. PMID: 23200980. DOI: 10.1016/j.cgh.2012.11.016

23 Yu J, Sadakari Y, Shindo K, Suenaga M, Brant A, Almario JAN, Borges M, Barkley T, Fesharakizadeh S, Ford M, Hruban RH, Shin EJ, Lennon AM, Canto MI and Goggins M: Digital nextgeneration sequencing identifies low-abundance mutations in pancreatic juice samples collected from the duodenum of patients with pancreatic cancer and intraductal papillary mucinous neoplasms. Gut 66(9): 1677-1687, 2017. PMID: 27432539. DOI: 10.1136/gutjnl-2015-311166

24 Kanda M, Knight S, Topazian M, Syngal S, Farrell J, Lee J, Kamel I, Lennon AM, Borges M, Young A, Fujiwara S, Seike J, 
Eshleman J, Hruban RH, Canto MI and Goggins M: Mutant gnas detected in duodenal collections of secretin-stimulated pancreatic juice indicates the presence or emergence of pancreatic cysts. Gut 62(7): 1024-1033, 2013. PMID: 22859495. DOI: 10.1136/gutjnl-2012-302823

25 Suenaga M, Dudley B, Karloski E, Borges M, Irene Canto M, Brand RE and Goggins M: The effect of pancreatic juice collection time on the detection of kras mutations. Pancreas 47(1): 35-39, 2018. PMID: 29200129. DOI: 10.1097/MPA.0000000000000956

26 Garud SS and Willingham FF: Molecular analysis of cyst fluid aspiration in the diagnosis and risk assessment of cystic lesions of the pancreas. Clin Transl Sci 5(1): 102-107, 2012. PMID: 22376266. DOI: 10.1111/j.1752-8062.2011.00312.x

27 DNA abnormalities. Interpace diagnostics: Pandna. Available at: https://pancragen.com/pancragen/pandna/

28 How pancragen works. Interpace diagnostics: Pancragen. Available at: https://pancragen.com/how-it-works/
29 Sadakari Y, Kanda M, Maitani K, Borges M, Canto MI and Goggins M: Mutant kras and gnas DNA concentrations in secretin-stimulated pancreatic fluid collected from the pancreatic duct and the duodenal lumen. Clin Transl Gastroenterol 5(11): e62, 2014. PMID: 25393586. DOI: 10.1038/ctg.2014.14

30 Iguchi H, Sugano K, Fukayama N, Ohkura H, Sadamoto K, Ohkoshi K, Seo Y, Tomoda H, Funakoshi A and Wakasugi H: Analysis of ki-ras codon 12 mutations in the duodenal juice of patients with pancreatic cancer. Gastroenterology 110(1): 221-226, 1996. PMID: 8536860. DOI: 10.1053/gast.1996.v110.pm8536860

Received June 8, 2020

Revised June 26, 2020

Accepted June 29, 2020 